\title{
Combining Checkpoint and Process Learning Analytics to Support Learning Design Decisions in Blended Learning Environments
}

\author{
Rogers Kaliisa ${ }^{1}$, Anders Kluge ${ }^{2}$, Anders I. Mørch ${ }^{3}$
}

\begin{abstract}
Learning analytics (LA) constitutes a key opportunity to support learning design (LD) in blended learning environments. However, details as to how LA supports LD in practice and information on teacher experiences with LA are limited. This study explores the potential of LA to inform LD based on a one-semester undergraduate blended learning course at a Norwegian university. Our findings indicate that creating valuable connections between LA and LD requires a detailed analysis of student checkpoints (e.g., online logins) and process analytics (e.g., online content and interaction dynamics) to find meaningful learning behaviour patterns that can be forwarded to teachers in retrospect to support the redesign of courses. Moreover, the teachers in our study found the LA visualizations to be valuable for understanding student online learning processes, but they also requested the timely sharing of aggregated LA visualizations in a simple, easy-to-interpret format, yet detailed enough to be informative and actionable. We conclude the paper by arguing that the potential of LA to support LD is improved when multiple levels of LA are considered.
\end{abstract}

\footnotetext{
Notes for Practice

- The effective use of learning analytics to support learning design requires a combination of different levels of learning analytics to provide richer insight into student online learning processes.

- The specific learning analytics visualizations should consider the pedagogical intentions of the course (i.e., to make learning design decisions based on theory) and the needs of the teachers, rather than specific analytics or other technical considerations.

- For learning analytics visualizations to meet the intended purpose of supporting learning design, they should be provided in a timely and simplified manner.

\section{Keywords}

Learning analytics, learning design, blended learning, teachers, Canvas, social network analysis, text network analysis
}

Submitted: 12/10/19 - Accepted: 06/07/20 - Published: 17/12/20

Corresponding author ${ }^{1}$ Email: rogers.kaliisa@iped.uio.no Address: Department of Education, University of Oslo, P.O. Box 1072 Blindern, 0317 , Oslo, Norway, ORCID ID: https://orcid.org/0000-0001-6528-8517

${ }^{2}$ Email: anders.kluge@iped.uio.no Address: Department of Education, University of Oslo, P.O. Box 1072 Blindern, 0317, Oslo, Norway, ORCID ID: https://orcid.org/0000-0001-5092-5819

${ }^{3}$ Email: anders.morch@iped.uio.no Address: Department of Education, University of Oslo, P.O. Box 1072 Blindern, 0317, Oslo, Norway, ORCID ID: https://orcid.org/0000-0002-1470-5234

\section{Introduction}

The dynamics between learning analytics (LA) and learning design (LD) have garnered interest among educational technology researchers and practitioners (Michos, Hernández-Leo, \& Albó, 2018; Nguyen, Rienties, Toetenel, Ferguson, \& Whitelock, 2017). This has been in part due to the increasing demand from higher education providers for teachers to apply evidenceinformed approaches and to provide better quality and tailored learning experiences to their students (Alhadad \& Thompson, 2017; Bennett, Agostinho, \& Lockyer, 2015; Dobozy \& Cameron, 2018). Teachers' usual practice is to rely on insights from summative assessments, course evaluations, and personal experience to make pedagogical decisions (Bakharia et al., 2016). However, LA can potentially provide teachers with timely feedback about student learning, which can contribute to informed pedagogical decisions and improved student performance in educational programs (Macfadyen \& Dawson, 2010). Consequently, there is an imperative among educational technology researchers to explore the possibilities of combining LA 
and LD to support teachers with timely and informed teaching and learning decisions (Griffiths, 2017; Law et al., 2017). However, despite substantial progress and interest in connecting these two areas of research, there is still much to explore about the potential of LA to support LD. One major methodological limitation within existing studies is the use of aggregated activity metrics (i.e., page views, logins, and time spent on tasks) to analyze LD; little emphasis has been placed on the process and the actual learning content. Moreover, little attention has been given to how teachers perceive and use the insights generated from LA data and visualizations to inform their LD decisions. The research reported in this paper investigates the potential of leveraging multiple LA sources to help teachers make informed LD decisions. Using the example of LD in a university course, we investigate how multiple levels of LA can lead to a richer understanding of student online learning processes and how these insights can be used by teachers to make informed LD decisions.

As for our contribution to the current research in this area, we propose that creating valuable connections between LA and LD requires a detailed analysis of student checkpoints and process analytics, as doing so adds scope for a more holistic and deeper understanding of the teaching and learning process. In this study, we use quantitative data (e.g., social network analysis), and in-depth interviews with teachers to enable a qualitative interpretation of our claims. The rest of the paper is organized as follows. We start with a brief overview of LA and LD and the relationship between them. We then present the existing research connecting these two areas. Next, we present the methodology and report the results and discussion. In the interests of space, the results are presented and discussed concurrently with the existing research. The paper concludes by discussing the key implications of combining LA and LD as well as suggestions for future research.

\section{Background}

The growing adoption of educational technologies (e.g., learning management systems or LMSs) and online learning approaches (e.g., massive open online courses [MOOCs] and content-based learning environments) have led to a greater quantity of data about students and their contexts. For example, student interactions with course content (e.g., tasks, resources, and forums) can be captured, stored, analyzed, and used as indicators of teaching quality (e.g., how the enacted teaching approaches align with learning outcomes; Lockyer, Heathcote, \& Dawson 2013; Gašević, Dawson, Rogers, \& Gašević, 2016) and to create predictive models of student learning (Macfadyen \& Dawson, 2010). Lockyer et al. (2013) suggested two different classes of analytics: 1) checkpoint analytics, which is concerned with tracing student access to necessary course content and pages (e.g., page views, online course logins, file downloads, and time spent on tasks); and 2) process analytics, which looks at the way students complete learning tasks (e.g., online discussion interactions). Such data can be provided to teachers in the form of visualizations, tables, and reports to support them with retrospective insight into teaching and learning outcomes (Ifenthaler, Gibson, \& Dobozy, 2018) and to reveal student cognitive and social learning processes (Kaliisa, Mørch, \& Kluge, 2019). This data can be used by teachers to generate predictive insights and to use as a benchmark for providing adaptive feedback at a fine-grained level, thus supporting personalized interventions (Law et al., 2017; Rienties, Cross, \& Zdrahal, 2017) and fully integrating curricular decision-making into the digital learning experience (Ifenthaler, Gibson, \& Dobozy, 2018).

Nonetheless, the digital footprints captured by LA tools are not without shortcomings. For example, LA cannot solely explain the success or failure of a particular learning activity through algorithms alone since numbers (i.e., quantitative approaches) do not provide context (Macfadyen \& Dawson, 2012) and do not speak for themselves (Wise \& Shaffer, 2015). Moreover, LA offers teachers and researchers limited insight into the systematic understanding of learner behaviour (Knight, Shum, \& Littleton, 2014) and productive learning processes. We argue that to make sense of and to identify meaningful patterns, an explicit theory that illustrates pedagogical information is needed. In this respect, LD has been suggested as a potential pedagogical framework through which to bridge the gap between the information provided by LA and the pedagogical designs created by teachers.

To delimit the scope of this paper, we adopt Conole's definition, which conceptualizes LD as a structure that supports teachers in their preparation and describes the course objectives, activities, assessments, and resources that students and teachers undertake in the context of a unit of learning (Conole, 2012). Consequently, LD creates the conditions for a learning environment that could potentially support teachers in making pedagogically informed decisions while planning, preparing, and writing about the later enactment (Agostinho, 2011). However, although LD has the potential to highlight pedagogical intentions, it fails to consider student learning processes and engagement in an ongoing course at a fine-grained level of analysis (Lockyer et al., 2013). In other words, few built-in best practices exist to evaluate the effects of the designs in comparison to the intended learning and teaching objectives. The connection between LA and LD is thus gaining momentum, with the expectation that the former can support inquiries into student learning activities (Bakharia et al., 2016; Mor, Ferguson, \& Wasson, 2015) and assessments of LD in context (Shibani, Knight, \& Shum, 2019). 


\section{Related Research and Identified Gaps}

\subsection{Blended Learning and Learning Analytics}

Blended learning (BL) is a pedagogical structure that combines traditional face-to-face instruction with computermediated/online delivery of content and instruction (Bonk \& Graham, 2012). In BL structures, due to the variety of online and face-to-face activities, it may be challenging for teachers to maintain awareness of certain aspects of the learning process (e.g., student progress, and whether class activities in practice deviate from the original plan in theory), particularly for online learning components (Hernández-Leo, Martinez-Maldonado, Pardo, Muñoz-Cristóbal, \& Rodríguez-Triana, 2019). One possible way to support teachers in dealing with the complexity of BL structures is the use of LA to help make certain aspects of the online learning components visible to support teachers' LD decisions. In the next section, the possible role that LA could play to support teachers' LD decisions in BL contexts is discussed.

\subsection{The Interplay Between Learning Analytics and Learning Design}

The interplay between LA and LD has gained considerable interest among educational technology researchers over the past few years (Mangaroska \& Giannakos, 2018). For example, Rienties et al. (2017) evaluated the weekly LD data of 2,111 learners in four language studies classes and found that individual course design explained $55 \%$ of the variance in weekly online engagement. In another study, Rienties and Toetenel (2016) linked 151 modules taught at The Open University (OU), in which 111,256 students were enrolled, and found that LD was a strong predictor of student satisfaction. Nguyen et al. (2017), who studied 74 modules to examine the impact of assessment design on student engagement, focusing on fine-grained weekly LD data, took a similar approach. Their study indicated that the course workload for other activities diminished after assessment activities were introduced. Additionally, Nguyen et al.'s (2018) work complement previous studies by linking the timing of student engagement to LD and academic performance. The findings revealed a mismatch between how instructors designed activities for learning and how students studied in reality. Moreover, Haya, Daems, Malzahn, Castellanos, and Hoppe (2015) demonstrated the value of an approach that combines social networks and content analysis to support LD decisions by providing indicators that support teachers in their assessment of their LDs.

In another example, Melero, Hernández-Leo, Sun, Santos, and Blat (2015) used a case study of location-based games and presented an LD dashboard that provided teachers with the necessary data to make evidence-based LD decisions. As with Haya et al. (2015), the study illustrated how alignment between LA and LD can support effective pedagogical decision-making. Rodríguez-Triana et al. (2015) proposed a monitoring-aware, pattern-based design process that allows teachers to benefit from the outputs of LA to improve their LD. Similarly, using examples of computer-based support tools, McKenney and Mor (2015) argued that the retrospective analysis of LA can support pedagogy-driven data collection and analysis, which could in turn offer insight into learning and teaching practices. This claim is corroborated by Fritz (2016) who found that the data generated by an LMS can be used by teachers and students as a real-time proxy to support effective course design practices. Meanwhile, Kaliisa, Kluge, and Mørch (in press b) more recently explored university teachers' LA-LD perspectives at two Norwegian universities. Findings revealed that teachers appreciated the formative and normative value of LA to provide more objective evidence about students' learning patterns which could lead to timely course design decisions.

Recent research has begun to synthesize the corpus of existing studies that explores the connection between LA and LD. For instance, Mangaroska and Giannakos (2018) reviewed 43 empirical studies on LA for LD; they depicted ongoing design patterns and detected learning phenomena (i.e., moments of learning or misconception) arising from the connection between LA and LD. Moreover, to aid LA-LD alignment, a review of 18 LA frameworks (Kaliisa, Kluge, \& Mørch, in press a) found that research has focused on providing tools and conceptual frameworks to inform the connection between LA and LD (Bakharia et al., 2016; Eradze, Rodriguez Triana, \& Laanpere, 2017; Hernández-Leo et al., 2019; Lockyer et al., 2013; Persico \& Pozzi, 2015; Gunn, McDonald, Donald, Nichols, Milne, \& Blumenstein, 2017) within online and BL settings.

While the research and interest in exploring the dynamics between LA and LD is increasing, few empirical studies have demonstrated how this alignment between LA and LD happens in practice. Most of the existing studies that combine LA and LD are based on aggregated data from large datasets - for example, from MOOCs and other distance learning programs (Nguyen et al., 2017) - and system logs (i.e., course logins, page views, and resource access). As noted by Mangaroska and Giannakos (2018), little attention has been paid to the analysis of content data (i.e., teaching and learning concepts) and how these elements can be used to define and identify meaningful learning behaviour patterns and interactions that can be retrospectively forwarded to teachers to support the redesign of their courses. An even smaller amount of research (see Michos, Hernández-Leo, \& Albó, 2018; Rienties \& Toetenel, 2016) has examined how LA visualizations illustrate the impact of LD activities (i.e., data from student interaction with content) for teachers or sought information about teacher experiences with aligning LA and LD based on their generated outputs (Rodríguez-Triana, Martínez-Monés, Asensio-Pérez, \& Dimitriadis, 2015). The apparent scarcity of studies that use content data and teacher experiences to acquire a holistic understanding of the 
connection between LA and LD seems contrary to the documented evidence of utilizing different datasets (e.g. online discussions) to offer comprehensive insights and practical comments to support informed future course improvements (Kaliisa, Kluge, \& Mørch, in press b; Samuelsen, Chen, \& Wasson, 2019).

Thus, motivated to address these research problems, we aim to contribute to the literature with an empirical study on LA and LD linkages by considering multiple levels of analysis (i.e., course activity metrics, content data, and interaction dynamics data, hereafter referred to as checkpoint and process analytics) and how this could offer deeper insight to inform LD decisions. Besides, we aim to better understand teacher experiences with connecting LA and LD by sharing LA visualizations with them to spark discussions about LD. The objective of our study is to explore the relevance of LA for informing LD by answering the following research questions (RQ):

RQ1. Do LA visualizations generated from different sets of process and checkpoint analytics provide informative insights to support LD decisions?

RQ2. What are the teachers' perceived value of using LA visualizations as tools to evaluate and make timely and informed

LD decisions?

With reference to the review of 18 existing LA-LD frameworks (Kaliisa et al., in press a), we employed the checkpoint and process analytics framework as the lens through which to select, present, interpret, and discuss our results. This framework highlights the different levels of data (e.g., checkpoint and process analytics) that are the basis of the current study. We argue that such data is relevant for a meaningful understanding of student learning behaviour especially in BL environments, where teachers may lack cues to understand student online learning behaviours.

\section{Methods}

\subsection{Research Design and Participants}

We used a mixed-methods approach by integrating quantitative information (i.e., social network analysis and automated discourse analysis) and qualitative interviews with teachers. We argue that the combination of different sets of data and analytical approaches is a valuable tool to enable the validation of data gathered and claims made from different approaches (i.e., using text network analysis to investigate the implicit meanings from page views and social network interactions). The study's main data source stems from the discussion forum contributions posted via the Canvas LMS for a bachelor-level, blended-learning technology course offered at a Norwegian University. The course included 36 enrolled students and four teachers. The researchers received ethics approval from the national review board, and informed consent was gained from 30 students and four teachers whose data informed the analysis presented in this paper.

\subsection{Learning Design and Course Context}

The studied course focused on technology-enhanced learning at the bachelor level. It included compulsory weekly online discussions on eight topics (see Table 1) and face-to-face lectures over eight weeks. The discussions were conducted asynchronously, and all the subsequent messages in the thread were text only. Each week, the teachers initiated a new discussion thread based on the topic of the next lecture. Each student was expected to make two contributions, including at least one response to another student, every week. The course materials included videos and required reading.

\subsection{Data Collection and Analysis}

We extracted checkpoint analytics such as individual students' weekly action logs (e.g., page views and participation/entries) from Canvas's analytics. This data represented student visits to elements within a course (i.e., curriculum content or tools) and the nature of their participation in the online activities (e.g., a discussion forum). We used this data as a lens through which to review the process analytics. We performed a Pearson correlation analysis (Benesty, Chen, Huang, \& Cohen, 2009) to determine whether there was a significant correlation between the Canvas page views and student participation, as measured by their entries in the discussion forum (see Figure 2). Later we extracted process analytics by aggregating scores and counted activities such as discussion forum posts and the modelling of concepts through text network analysis (TNA) and social network analysis (SNA). This was intended to identify the interaction dynamics that evolved over the course of the collaborative online activities and the topics explored by the students within the networks.

\subsection{Social Network Analysis}

We extracted discussion forum data from the institutional LMS and reconstructed social network relationships based on student-student, student-teacher, and teacher-student interactions. This study involved the manual extraction of student discussions and interaction data (399 posts) from the LMS into a third-party social network visualization tool called NodeXL (Smith et al., 2009). Discussions were coded as vertices and edges using a Canvas link labelled "reply/go to theme." In this context, a vertex is defined as an engaged user, and an edge is defined as a connection between users. The coding process in 
NodeXL included all students who posted in the discussion forum. For example, if student S10 posted a message in response to the main discussion question (DQ), we coded it as (S10 $\rightarrow \mathrm{DQ}$ ). Then, if student S8 posted a message in response to S10's post, we coded it as (S8 $\rightarrow$ S10). Following the SNA measures used in previous studies (Andersen \& Mørch, 2016), we used degree centrality measures to determine the number of ties an individual student actor had with other student actors in the network (Smith et al., 2009). Moreover, we used betweenness centrality to identify the students occurring within the shortest path between other nodes, which represented other students, who thus facilitated the spread or control of information within the network.

\subsection{Text Network Analysis}

Discourse analysis was used to unveil and categorize key concepts and topics that emerged from the students' weekly discussion posts and how they were connected to the course design (Haya et al., 2015). The analysis was performed through text network analysis, which converts textual artefacts into a network of topics based on the proximity of their representatives in a given text (Haya et al., 2015). We used InfraNodus, a web-based, open-source automation tool, which relies on a text network analysis algorithm to identify influential words and topical clusters (Paranyushkin, 2019). Prior to the analysis, we preprocessed the data in three key steps. First, the student contributions from each week were combined into one corpus file. Second, we performed text normalization or stemming, by which all the words in the text were converted into their lemmas to reduce redundancy and to bring different variations of certain words under the same common denominator. We also removed all the syntax information (e.g., "?") but maintained the paragraph structure. Last, we conducted Stop words removal for commonly used words (i.e. "as," "the," and "is") that do not carry additional meaning, as well as for numbers, pictures embedded in postings, user avatars and information, headers, and punctuation. Following these procedures, we performed a text analysis for each week, which produced directed network graphs (see Figure 1) in which the normalized words were nodes and the edges between them described the regularity with which they co-occurred in the analyzed documents. The unit of analysis was the weekly discussion theme or topic (see Table 1), which was used as a benchmark to identify relevant topics that connect to the pedagogical intent of the respective discussion.

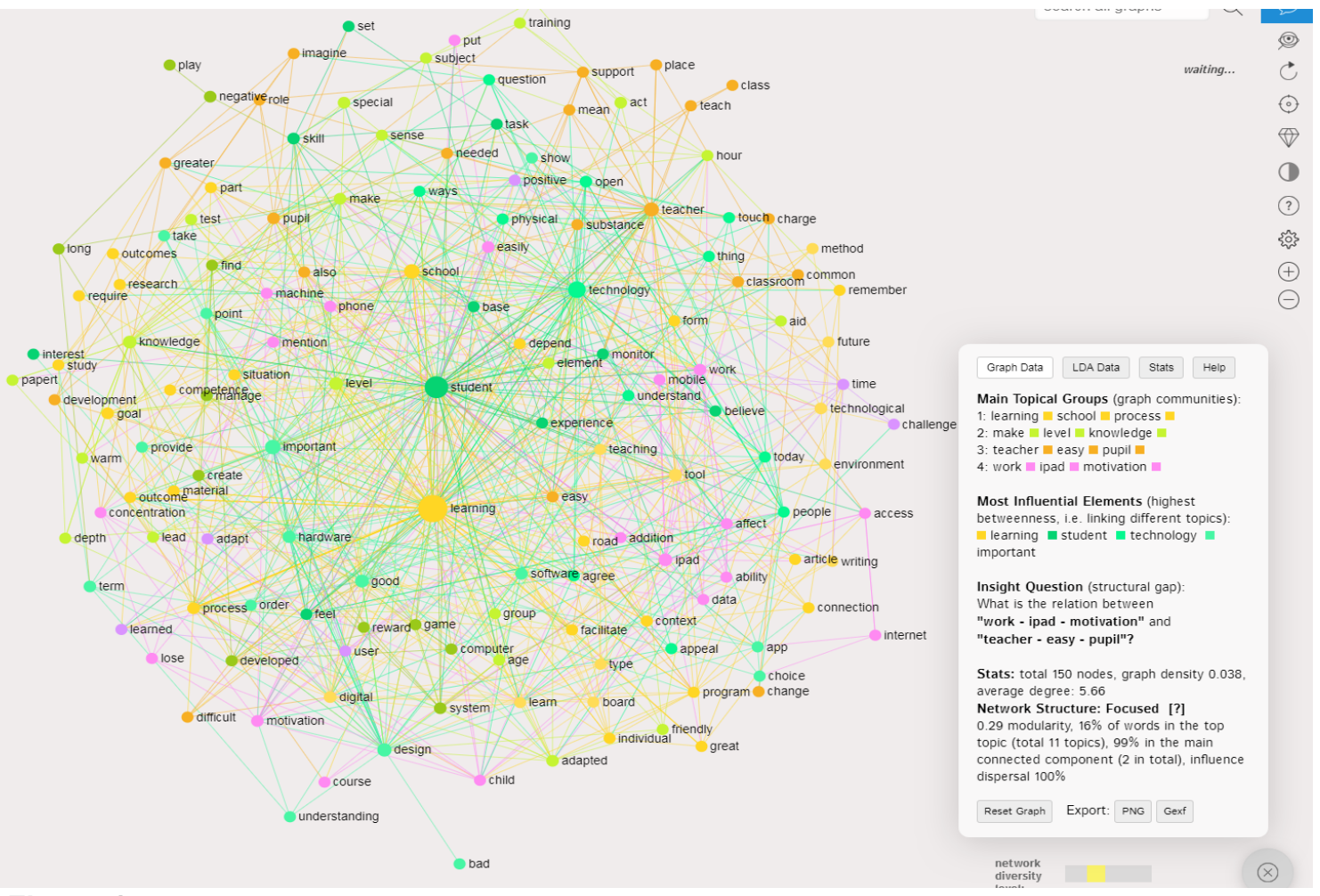

Figure 1. InfraNodus interface visualizing the main topics inside, and discourse structure of Week 7

\subsection{Interviews}

We conducted individual semi-structured interviews with the four teachers (three male, one female) who taught the course and stemming from the education faculty. Two of the teachers had more than 30 years of teaching experience in higher education, while the remaining two had a teaching background ranging between 5 and 10 years. None of the teachers had experience with 
using LA as part of their teaching. The interviews allowed us to identify feelings and perceptions of the participating teachers and to validate and assess the usability of the visualized checkpoint and process analytics for LD purposes. The four interviews, which lasted between 30 and 45 minutes, were conducted in person. Each of the teachers were shown visualizations from the online modules they had facilitated (e.g., Figure 1). This means that all interviewed teachers had a clear understanding of the module structure, the activity schedules, and the expected pedagogical outcomes. In other words, during the interviews, the teachers could bring contextual knowledge to the review of the LA visualizations since, as noted by Lockyer et al. (2013), the interpretation of such visualizations highly depends on the user's understanding of the context and the goals of the teacher. The interview protocol, devised based on the research questions and prior research on teachers' LA adoption (Rienties \& Toetenel, 2016), began with questions related to the teachers' general experiences of their LD throughout the semester. The main portion of the interview asked instructors to 1) critically study the provided LA visualizations, 2) make sense of them, 3) give their opinion on what they found useful or not useful, 4) discuss how such visualizations could inform their LDs, 5) explain when they would like to receive such visualizations, and 6) discuss the challenges associated with such visualizations. All interviews were audio-recorded and later transcribed.

\section{Results and Discussion}

\subsection{Descriptive Statistics of Checkpoint Analytics}

Figure 2 shows the student checkpoint analytics (i.e., page views and entries) over the course of the semester. The statistical analysis showed that the correlation between Canvas page views and participation (expressed as entries) was close to zero and hence not significant $(\mathrm{p}>.05)(\mathrm{r}=.06, \mathrm{p}=.760)$. For instance, as illustrated in the scatterplot, students S5, S30, S33, and S13 had the highest number of page views $(1053,1108,1072$, and 845, respectively), while students S1, S20, S23, and S34 recorded the lowest number of page views $(332,295,250$, and 361, respectively). However, concerning entries in the discussion forum, S17, S28, S29, S22, S14, S3, S9, and S34 recorded the highest number of entries (between 17 and 20), which is equivalent to the average number of posts (16) expected as per the LD. An interesting finding was that there was no overlap between the students with the most entries in the online discussion forum and the students with higher Canvas page views. Moreover, three of the students who recorded low participation in the discussion forum activities (S27, S7, and S6) had a slightly higher presence in Canvas, with their total page views amounting to 741, 755, and 745, respectively. These results suggest no clear pattern between average page views and participation rate. One potential explanation could be that some students made effective use of the Canvas environment, but that this use was not adequately represented by the total page views. Some students could have also used Canvas to submit an assignment without interacting with their classmates or accessing all the material made available by the teachers.

These results support the claims from previous studies that some learning traces, especially total time spent online, relate only weakly to student participation and their contributions to the online discourse (Macfadyen \& Dawson, 2010). However, this finding does not imply that checkpoint analytics is useless in understanding student online learning processes; rather, even though it could be an invaluable proxy for student engagement with the course content, researchers and practitioners need to acknowledge the caveats of using such data in isolation of more interpretive process analytics (Lockyer et al., 2013; Nguyen et al., 2018).

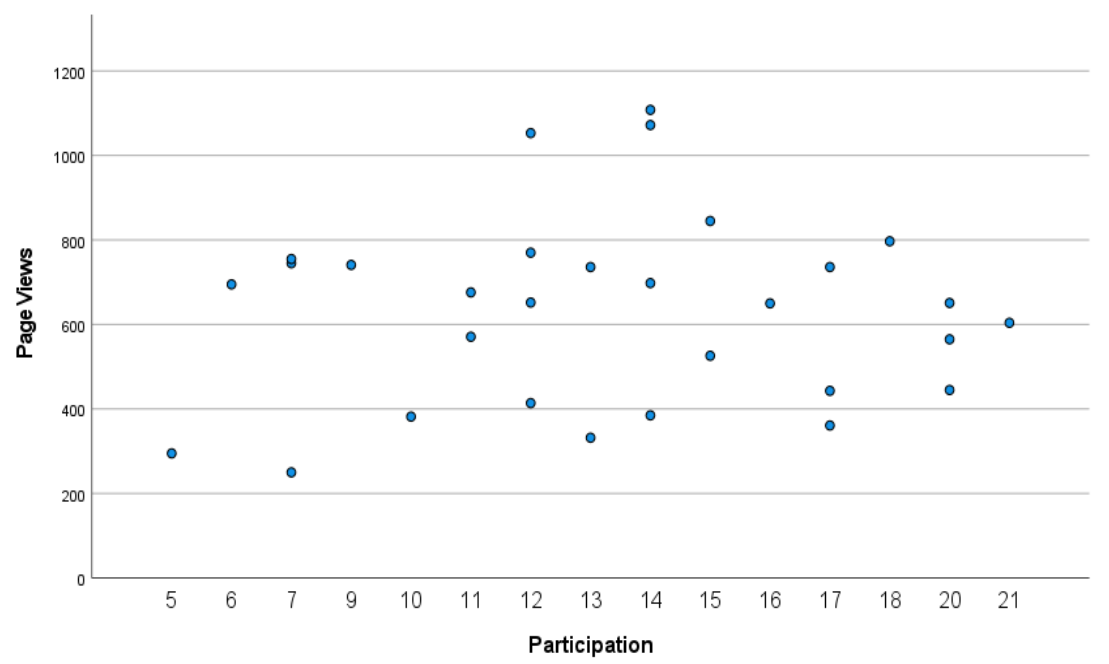

Figure 2. Scatter plot of students' Canvas page views and discussion entries during the semester 


\subsection{Social Network Analysis Findings}

We analyzed student interactions in the online discussion forum, as illustrated in the sociograms in Figure 3. The layout of the figures is based on the Harel-Koren Fast Multiscale algorithm, which produces undirected graphs with straight-line edges (Harel \& Koren, 2001). The figure provides an aggregated visual representation of the unweighted and undirected graphs, connecting 30 students and four teachers during the eight weeks of online discussion activities conducted on the Canvas platform. The size of the nodes corresponds to their degree centrality or the number of edges connected to them in the network. This means that the bigger a node is, the more messages that the student or teacher represented by that node sent and received. Furthermore, betweenness centrality was measured by the extent to which a node was more central to the main discussion question (DQ), which was very dense with numerous edges. For example, S13, S29, S14, S3, S17, S28, and S4 recorded the highest betweenness centrality between Weeks 1 and 7, respectively. Moreover, the figure also provides useful information about the weakly connected students across the eight weeks of discussion, which could be an early warning sign to help teachers detect students who are not complying with the course instructions.

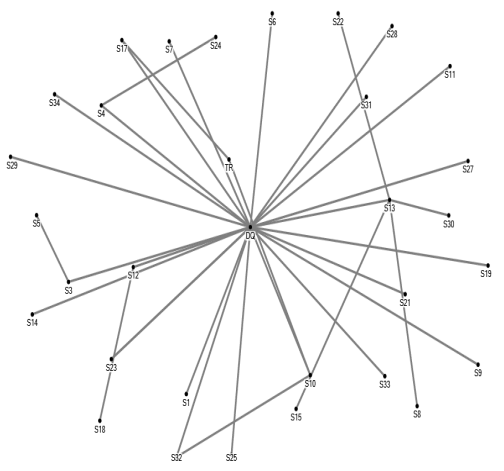

Week 1

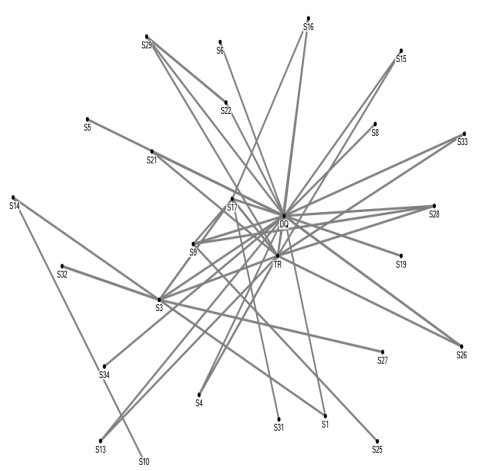

Week 4

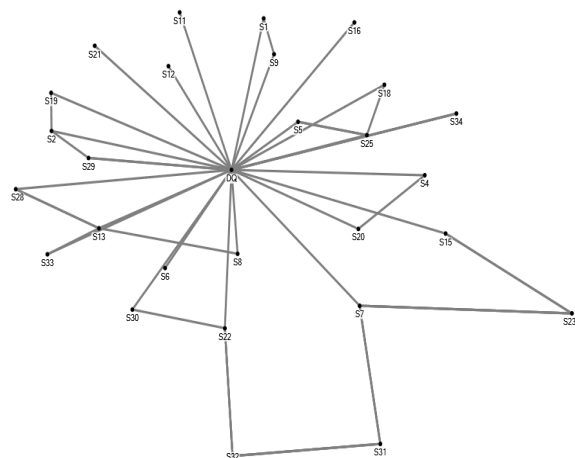

Week 2

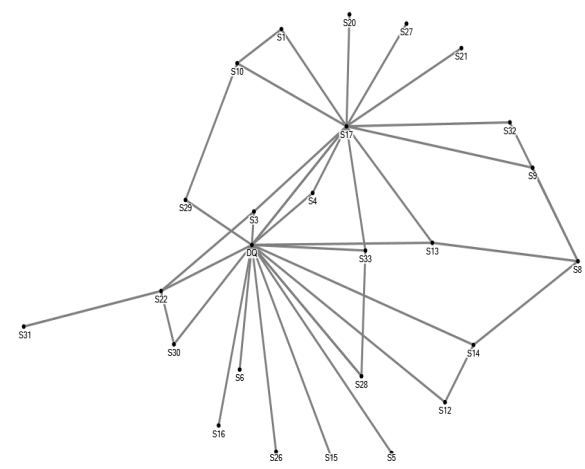

Week 5

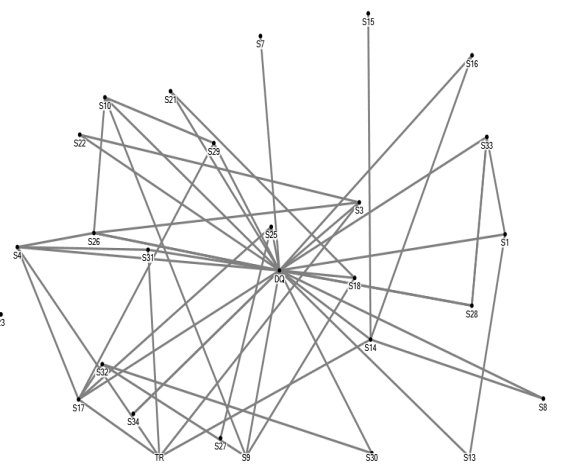

Week 3

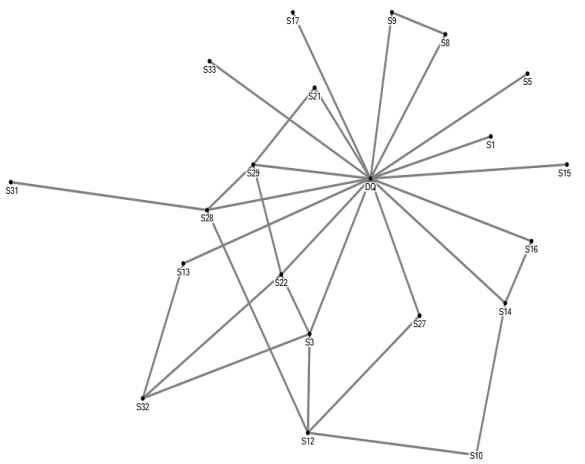

Week 6

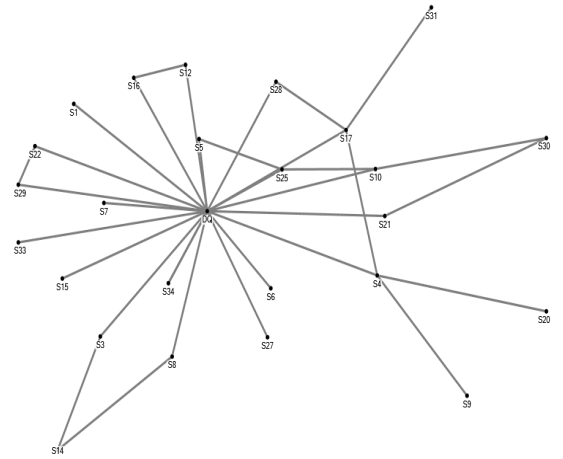

Week 7

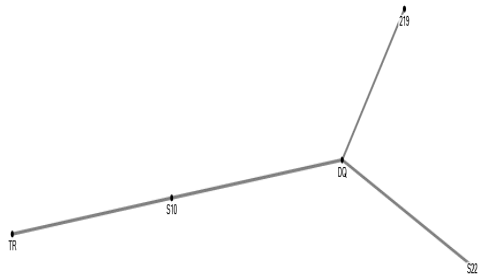

Week 8

Figure 3. Discussion forum networks across the eight weeks of the course. Each node represents a student who posted at least one contribution or provided at least one reply to another student.

The size of each node suggests the quantity of interactions associated with the student. 
Conversely, at the group level, the sociograms illustrate students' general interaction (social structure) across the eight weeks. For example, the Week 1 sociogram illustrates limited interaction among students, with most communication directed towards the original discussion question (DQ). This means that this interaction pattern was polarized from the intended LD of student-to-student interaction. However, a higher volume of interactions is observed in Weeks 2-7, with students and teachers interacting more than in Week 1 . In Week 4 , the average degree of centrality increased, which is depicted by enlarged nodes (e.g., S3, S17, and S9). This is possibly attributed to the teacher-centric pattern observed in Week 4. It is interesting to observe the dramatic drop in network density in Week 8, where only three students posted in the discussion forum. Unsurprisingly, this is attributed to the fact that the discussion during Week 8 was not compulsory, and very close to the end-of-semester examination. Thus, students opted not to post in the discussion forum. In line with previous studies (Rienties et al., 2017), this finding confirms that the teacher's course design could explain the variance in students' weekly online engagement. Such a finding implies that teachers should design courses with the awareness that the scheduling and instructions could affect student VLE behaviour.

Overall from a researcher's perspective, while the findings from the social network visualizations might not be surprising, their strength relies in creating a much easier-to-understand visual representation of large amounts of student information and interactions at a glance, thus enabling teachers to monitor what is happening in their courses and to make quick and informed LD decisions at a structural level. In other words, the social network visualizations could provide teachers with an opportunity to quickly detect early on whether students are complying with the instructional guidelines. Therefore, teachers can use this measure as a benchmark for adapting their teaching practice and for taking action either through whole-class or individualstudent scaffolding (Wise \& Jung, 2019). Moreover, the visualizations could act as a reflective resource for teachers to assess whether socio-constructivist educational goals (i.e., group discussion) have been accomplished (Macfadyen \& Dawson, 2010), since student-to-student interactions in online learning environments are a significant predictor of student success (Macfadyen \& Dawson, 2012). As shown in this study, by comparing the LD objectives, teachers can visually analyze the networks depicted in the sociograms to identify students who were highly or less engaged in the discussion forum, as defined by the teachers.

By examining the vertices and edges, teachers can see which students posted at least twice and commented on other student contributions. For example, if students followed the LD instructions provided by the teachers, then each student would have posted at least twice and interacted with at least one other student, obtaining a degree centrality of at least three. By gaining such insights from social network visualizations, teachers can implement strategic teaching interventions (e.g., splitting groups) to manipulate social structures and encourage student participation. Alternatively, the teacher can intervene to change the interaction dynamics by encouraging less central but engaged students to extend their network and thus have more centralfocal points to promote liveliness in the discussion. However, as highlighted in previous studies (Lockyer et al., 2013), meaningful interpretations of social network visualizations are only possible if the LD and the intent of the activities are made clear ahead of the analysis.

\subsection{Text Network Analysis Findings}

Aiming for further informative insight into the potential impact of LA visualizations on the revision of LDs, we performed an automated discourse analysis of student discussion contributions to detect the dominant concepts and terms used. Table 1 depicts the four main topical groups and influential concepts for each discussion theme across the eight weeks. One interesting observation gained from analyzing student discourse through a temporal dimension is that across the eight weeks, the concepts of "learning" and "technology" gained significant attention from the students and were sustained throughout the eight weeks of discussion (i.e., 1, 2, 3, 4, 5, and 7, and 2, 4, 5, and 7, respectively). The frequent presence of these concepts could imply that they are central and form the backbone for meaning circulation and for binding together clusters of terms within the discussion forum (Paranyushkin, 2019). This observation is unsurprising given that the name of the course is "Learning, Design and Technology." Moreover, it is logical that over the weeks, the most influential concepts were closely related to the discussion theme for the respective week. For instance, in Week 4 (see Figure 4), the key concepts of learning, school, knowledge, and technology were closely related to the three sub-questions posed by the teacher, which were related to the characteristics of learning at work, the technologies that support learning at work, and the differences and similarities between learning at work and learning at school or through education. Although such an observation might imply that the frequent presence of topics related to the discussion theme indicates highly relevant and valuable course discussions, we also think that this might have resulted from the LD, as every teacher emphasized the use of the course literature as the basis for the discussion. More precisely, such a finding could imply that the questions set by the course instructors have critical importance for and influence on student learning processes. 
Table 1. Weekly Discussion Topics, Topical Groups, Influential Elements, and Graph Density

\begin{tabular}{|c|c|c|c|}
\hline Weekly Discussion Topic & Topical Groups & $\begin{array}{l}\text { Influential Elements } \\
\text { (betweenness) }\end{array}$ & $\begin{array}{l}\text { Graph } \\
\text { Density }\end{array}$ \\
\hline $\begin{array}{l}\text { 1. The distinctions between } \\
\text { "knowledge," "skills," and } \\
\text { "dispositions" based on } \\
\text { J. S. Brown's video }\end{array}$ & $\begin{array}{l}\text { A. Learning, motivation, perspective } \\
\text { B. Knowledge, disposition, Brown } \\
\text { C. School, make, experience } \\
\text { D. Important, information, believe }\end{array}$ & $\begin{array}{l}\text { Knowledge, } \\
\text { learning, } \\
\text { information, } \\
\text { disposition }\end{array}$ & 0.055 \\
\hline $\begin{array}{l}\text { 2. Role of technology in } \\
\text { classroom experiences }\end{array}$ & $\begin{array}{l}\text { A. Task, solve, test } \\
\text { B. Learning, theory, good } \\
\text { C. Technology, thing, work? } \\
\text { D. Teacher, teaching, class }\end{array}$ & $\begin{array}{l}\text { School, technology, } \\
\text { learning? Teacher }\end{array}$ & 0.047 \\
\hline 3. Constructivism in practice & $\begin{array}{l}\text { A. Meaningful, building, Lego } \\
\text { B. Make, work, Minecraft } \\
\text { C. Learn, thing, ways } \\
\text { D. Learning, process, design }\end{array}$ & $\begin{array}{l}\text { Learning, building, } \\
\text { create, game? }\end{array}$ & 0.007 \\
\hline $\begin{array}{l}\text { 4. Social media and e-learning } \\
\text { in working life technologies } \\
\text { that support learning at work }\end{array}$ & $\begin{array}{l}\text { A. Knowledge, important, good } \\
\text { B. Time, teacher, lot } \\
\text { C. School, technology, remember } \\
\text { D. Learning, work, tool }\end{array}$ & $\begin{array}{l}\text { Learning, school, } \\
\text { knowledge, } \\
\text { technology }\end{array}$ & 0.114 \\
\hline $\begin{array}{l}\text { 5. Difference between } \\
\text { mechanical and digital } \\
\text { technology }\end{array}$ & $\begin{array}{l}\text { A. Reading, easy, read } \\
\text { B. Learning, theory, support } \\
\text { C. Technology, learn, digital } \\
\text { D. Time, today, book }\end{array}$ & $\begin{array}{l}\text { Learning, } \\
\text { technology, learn, } \\
\text { reading }\end{array}$ & 0.033 \\
\hline $\begin{array}{l}\text { 6. Advantages and } \\
\text { disadvantages of a digital } \\
\text { climate simulator }\end{array}$ & $\begin{array}{l}\text { A. Graph, model, understand } \\
\text { B. World, part, interesting } \\
\text { C. Student, task, show } \\
\text { D. Tool, science, imagine }\end{array}$ & $\begin{array}{l}\text { Simulator, student, } \\
\text { climate, graph }\end{array}$ & 0.034 \\
\hline $\begin{array}{l}\text { 7. Hardware design for the } \\
\text { learning process and learning } \\
\text { outcomes in schools }\end{array}$ & $\begin{array}{l}\text { A. Learning, school, process } \\
\text { B. Make, level, knowledge } \\
\text { C. Teacher, easy, pupil } \\
\text { D. Work, iPad, motivation }\end{array}$ & $\begin{array}{l}\text { Learning, student, } \\
\text { technology, } \\
\text { important }\end{array}$ & 0.038 \\
\hline $\begin{array}{l}\text { 8. Questions regarding the } \\
\text { examination (non-obligatory) }\end{array}$ & $\begin{array}{l}\text { A. Lecture, summarize, latest } \\
\text { B. Exam, thought, group } \\
\text { C. Sensible, penitent, grasp } \\
\text { D. Answer, template, institute }\end{array}$ & $\begin{array}{l}\text { Group lecture, } \\
\text { exam, thought }\end{array}$ & 0.023 \\
\hline
\end{tabular}

Thus, from an LD perspective, by examining the textual discourse and network structure, teachers may have an early signal by quickly identifying the text's main agenda, especially in connection to the intended pedagogical intent. In particular, the text networks could enable teachers to acquire an overall understanding of the discussion topics and specific, representative points. Consequently, the teacher can get a signal regarding the kinds of topics provoked by the instructional content of a lesson, thus supporting future instructional decisions for the course and providing a basis for adaptations and scaffolding students (Haya et al., 2015). Such possibilities are not feasible through traditional assessment and evaluation practices, which usually take place at the semester's end (Bakharia et al., 2016). 


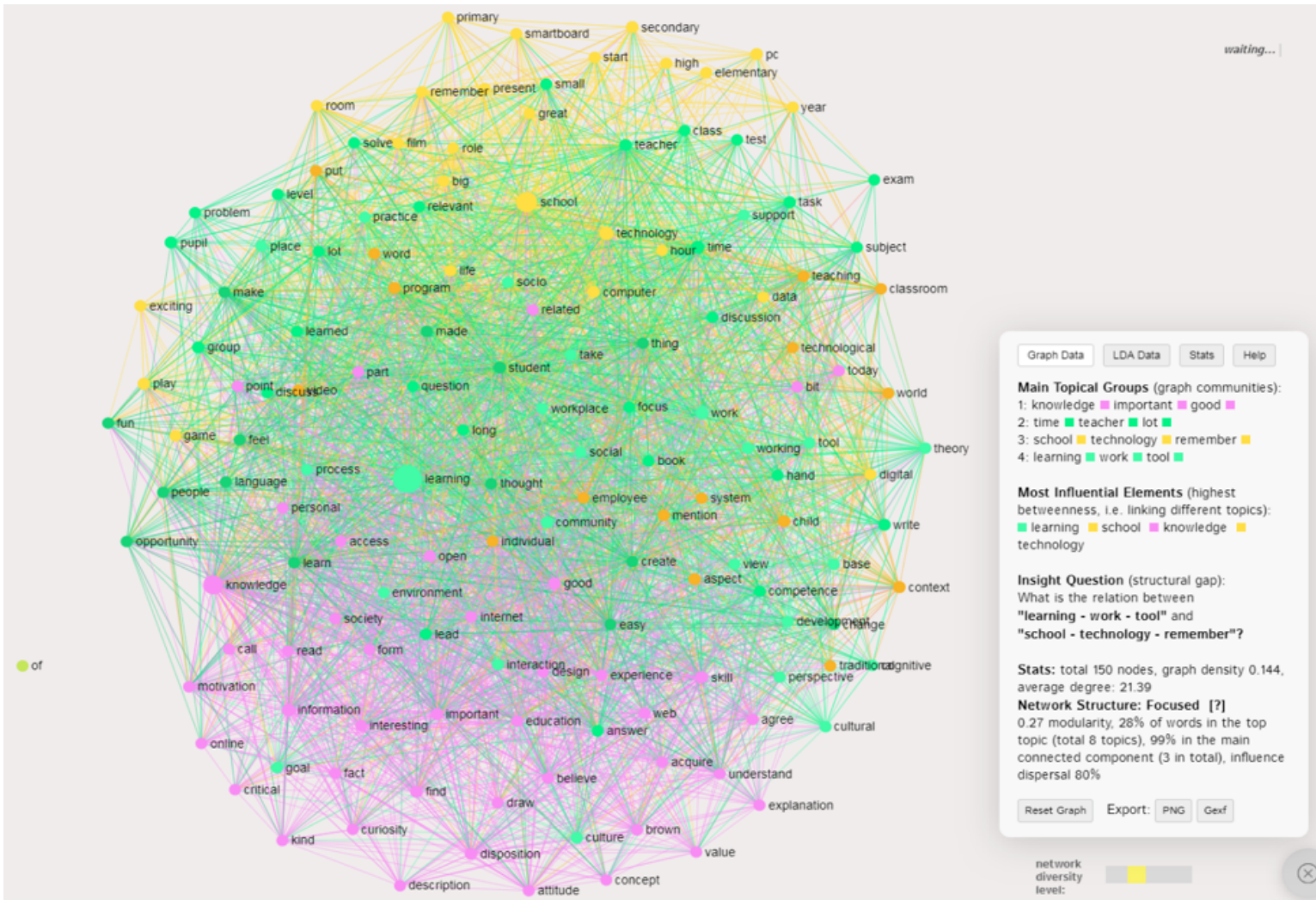

Figure 4. InfraNodus interface visualizing Week 4's main topics and graph metrics

\subsection{Teachers' Interview Results}

The four teachers were invited to reflect on the perceived value of using LA visualizations. Two broad themes surfaced across these interviews: 1) the value of LA visualizations; and 2) challenges concerning LA visualizations. These are further discussed below.

\subsubsection{Theme 1: Value of LA Visualizations}

The value of LA visualizations perceived by the teachers were categorized broadly into the three sub-themes of supporting $\mathrm{LD}$, detecting the quality of online discourse, and facilitating teacher-student discussions. Table 2 illustrates the themes and sample extracts of the quotes as exemplifications of themes identified.

Table 2. Perceived Value of LA Sub-Themes, Sample Extracts, and Interview Questions

\begin{tabular}{|c|c|c|}
\hline Sub-Themes & Sample Extracts & Interview Questions \\
\hline $\begin{array}{l}\text { Supporting } \\
\text { LD decisions }\end{array}$ & $\begin{array}{l}\text { "The networks can tell me if students responded to } \\
\text { the discussion forum as asked by my looking at the } \\
\text { nature of the networks or number of nodes" (T4) }\end{array}$ & \multirow{3}{*}{$\begin{array}{l}\text { What is your impression } \\
\text { about these visualizations? } \\
\text { How do they link to the } \\
\text { intended discussion } \\
\text { activities? } \\
\text { How would you use these } \\
\text { visualizations to inform } \\
\text { your design practice? }\end{array}$} \\
\hline $\begin{array}{l}\text { Detecting the } \\
\text { quality of } \\
\text { online } \\
\text { discourse }\end{array}$ & $\begin{array}{l}\text { "The visualizations highlight very high presentation, } \\
\text { of course, content knowledge and provide a } \\
\text { benchmark for gaining a comprehensive picture of } \\
\text { students' online learning processes" (T1) }\end{array}$ & \\
\hline $\begin{array}{l}\text { Facilitating } \\
\text { teacher- } \\
\text { student } \\
\text { discussions }\end{array}$ & $\begin{array}{l}\text { "For example, for this week, I don't see the word } \\
\text { 'skills,' yet I expected it to be central to the } \\
\text { discussion; I can then ask students if they found the } \\
\text { term hard to conceptualize and then build a } \\
\text { discussion around that" (T2) }\end{array}$ & \\
\hline
\end{tabular}

Supporting Learning Design Decisions: The teachers found that the information provided by the LA visualizations could be used to inform the redesign of their courses and face-to-face lectures. For example, two teachers expressed that the 
visualizations could be useful in understanding how students responded to the tasks provided and how their responses related to the pedagogical intentions of the task. For instance, one teacher denoted the importance of text and social network visualizations in identifying the most and least active students as well as student knowledge of the course content ahead of the classroom meetings. In addition, on the checkpoint analytics provided by Canvas, one teacher said that these kinds of analytics can provide information about the design of the course that could support the modification of in-classroom lectures. Similarly, T4 mentioned that according to the text network visualizations (Week 3), some key concepts from the required readings such as "lego" were detected under the main topical groups, which means that the students had utilized the required course literature. In particular, teachers thought that such visualizations are handy for very large courses. As T3 noted, "In a course of about 200 students, where it is unrealistic to read through all the comments, the visualizations could be absolutely very productive."

Facilitating Teacher-Student Discussions: Teachers valued the potential of LA visualizations (e.g., text and network analysis) to prompt discussions between students and teachers. For example, T2 mentioned that during the lectures, the text network analysis outputs could be used to create a discussion around the structural gap identified by the text network analysis tool InfraNodus (see Table 1). In this regard, the teachers expressed that to achieve the best outcome of the LA visualizations, they would need to share the outputs with the students throughout the course. One representative comment came from T1 who pointed out, "I think it could be interesting to show them to students, tell them that this represents what they think, and then have a discussion around it." Another teacher stressed the same point: "I find the visualizations useful for me as a teacher, but it is necessary that the students are also presented with the same output" (T3).

Detecting the Quality of Online Discourse: LA visualizations could help teachers understand student online learning processes and how they are connected to the LD. As one teacher commented, social network visualizations could provide insight into which topics and questions generate debate among students. More so, T3 stated, "In theory, the importance of something like this is to identify a thread that most of the students responded to and then take a close look at that thread."

\subsubsection{Theme 2: Challenges of LA Visualizations}

The teachers highlighted some challenges associated with the potential use of LA visualizations. These challenges were categorized broadly into two sub-themes: 1) sophisticated LA visualizations; and 2) unclear demonstration of student knowledge construction processes (see Table 3).

Table 3. Challenges of LA Visualizations Subthemes, Sample Extracts, and Interview Questions

\begin{tabular}{|c|c|c|}
\hline Sub-Themes & Sample Extract & Interview Questions \\
\hline $\begin{array}{l}\text { Sophisticated LA } \\
\text { visualizations }\end{array}$ & $\begin{array}{l}\text { "The text networks are so dense and } \\
\text { contain so many links so I cannot } \\
\text { interpret them well" (T2) }\end{array}$ & $\begin{array}{l}\text { What are the challenges } \\
\text { associated with the use of } \\
\text { these LA visualizations? }\end{array}$ \\
\hline $\begin{array}{l}\text { Unclear } \\
\text { demonstration of } \\
\text { student knowledge } \\
\text { construction processes }\end{array}$ & $\begin{array}{l}\text { "What I still miss from the visualizations } \\
\text { is the actual excerpts from students' } \\
\text { discussions and tracking of student } \\
\text { knowledge-building processes" (T3) }\end{array}$ & $\begin{array}{l}\text { What kind of visualizations } \\
\text { would you like to receive to } \\
\text { inform your practice? }\end{array}$ \\
\hline
\end{tabular}

Sophisticated LA Visualizations: While teachers found the LA visualizations interesting, three of them were concerned about their sophisticated nature, which made their potential use in practice difficult. For example, T1 felt that the text networks were so dense and contained so many links that the detail impeded the extraction of meaningful insights, especially for LA novices. In this regard, T2 expressed the need for aggregated metrics for easy interpretation.

Demonstrating Student Knowledge Construction Processes: Another challenge concerned the failure of the visualizations to demonstrate student knowledge development processes. Thus, teachers voiced concerns about their utility in understanding student learning processes and informing LD. In this regard, teachers asked for additional and more in-depth information to support the meaningful translation of the visualizations into relevant pedagogical actions.

Overall, despite some reservations, teachers explicitly expressed the value of the LA visualizations in several ways. For example, the teachers found them to be informative about the flow of the course, which could be used to make necessary modifications throughout the process. According to the teachers, the visualizations raised their awareness of the quality of the student online discourse by identifying the main themes and their magnitude in online discussions. The LA visualizations could also facilitate discussions between teachers and students. However, for LD decisions to be made based on these outputs, the teachers emphasized the need to share the LA visualizations in real time while the course is running. For example, in the current study, the presentation of the visualizations at the end of the course limited the ability to make changes to the course during the semester. Some teachers felt that if they had received the visualizations earlier, they could have made changes to the design of their courses. While the regular provision of data to the teachers might be overwhelming or require a lot of work 
for the researcher, using automated approaches could address the challenge. Moreover, teachers suggested the need to keep LA visualizations simple but with enough details to gain a richer understanding of student learning processes. Such insights from the teachers validate and confirm what Rienties and Toetenel (2016) found regarding the need to present LA visualizations in a pedagogically meaningful manner to allow teachers to make connections between them and their LDs. Moreover, as emphasized in previous research (Rodríguez-Triana et al., 2015), it is important to keep the visualizations simple so that teachers can derive meaning from them. In this regard, researchers and LMS designers should not provide data to teachers for them to interpret but instead provide them with answers to the questions they seek to answer about the teaching and learning processes (Buckingham Shum, Ferguson, \& Martinez-Maldonado, 2019). This can be achieved through LA plugins that provoke simple but productive sense-making by the teachers (Martinez-Maldonado, Kay, Yacef, \& Schwendimann, 2012).

\section{Limitations and Future Work}

Some limitations affect the generalizability and interpretation of the findings of this exploratory study. First, the conclusions of the study are limited by its focus on data collected from a single course, with a small sample size of 30 students and four teachers from the same academic discipline. LA needs do, of course, vary between different disciplines. Second, the lack of consent from the six students limited the ability to have a full network. Nonetheless, the non-consenting students never participated in all discussions and were not part of the central discussion actors. Lastly, presenting the visualizations at the end of the course limited the teachers' ability to make changes to the LD during the course. These limitations will inform the next phase of our LA-LD research. Several further research lines have been identified:

1. Sharing LA visualizations with teachers and students during the course to support timely LD adaptations

2. Integrating teacher-user friendly LA visualization tools (e.g., Quantext [quantext.org]) in the Canvas LMS to provide simple and pedagogically relevant visualizations of checkpoint and process analytics, which would support easier application by the teachers

3. Providing visualizations representing student knowledge networks to both teachers and students

4. Using larger samples to validate these initial findings

\section{Conclusion}

In this study, we examined the potential of LA as a means to provide important insights to help teachers improve their LDs. To do so, we analyzed Canvas activity metrics, discussion forum content, and interactions from a semester-long bachelor-level course at a Norwegian University. The first research question investigated whether LA visualizations generated from different sets of process and checkpoint analytics could provide informative insights to support LD decisions. The findings reveal that analyzing different levels of analytics (e.g., process and checkpoint) could provide important information about student online learning processes (i.e., course access, course performance, discussion forum activities, and topics discussed), which can be used as a reflective resource by teachers to make informed LD decisions. Some of our findings indicated a discrepancy between checkpoint analytics (e.g., the total time spent online and actual student participation). This finding demonstrates that it is important to complement checkpoint analytics with a more focused analysis (i.e., process analytics) that considers the student's actual information processing and knowledge application (Lockyer et al., 2013).

The second research question explored teachers' perceived value of using LA visualizations as tools to evaluate and make productive, timely, informed LD decisions. The findings indicate that teachers perceive LA visualizations as important for gaining insight into the flow of the course, identify which LD elements should be revised, initiate teacher-student interactions, and assess the quality of the online discourse. Teachers argued that such insights could support inquiry into student learning activities and improve the relevance of in-class lectures. The teachers also voiced concerns about the LA visualizations; in particular, they were concerned about the sophisticated visualizations and the failure to demonstrate student knowledge construction processes. Thus, they suggested providing clear, more in-depth information (e.g., knowledge development networks) and simplified LA visualizations, which would hide unnecessary complexity but be detailed enough to be informative and still leave opportunities for teacher interpretation.

We extended the existing research on LA and LD in four ways. First, from a research perspective, this study provides detailed descriptions of how researchers can simultaneously use multiple levels of analytics to provide insights into the status of student online learning activities and enable relevant interpretations of the results. The combination of different approaches in this study supports the general claim that the most benefit can be expected from combining different types of analytics data and techniques since doing so provides a richer basis for understanding the connection between LA and LD (Haya et al., 2015). Second, from a teacher perspective, this study demonstrates how teachers can generate valuable insight into student learning activities based on LA visualizations (i.e., social and text network diagrams), which provides them with an opportunity to reflect on their practice and make timely adaptations to their LDs. Third, we provide teacher perspectives on LA visualizations 
and their impact on LD. The issues highlighted by instructors (i.e., the need to keep visualizations simple) offer useful, practical guidelines to researchers and LA tool designers regarding the nature of the outputs and tools needed by teachers. Finally, we used the checkpoint and process analytics framework as a guide for the collection and analysis of relevant analytics data and how it connects to pedagogical objectives. While this framework is at a high descriptive level, suggesting no tools to support the collection and analysis of relevant analytics, we found it useful in providing a lens through which to select, interpret, and gain actionable insights for the refinement and redesign of learning activities. In this regard, we have contributed towards the limited validation of LA frameworks in practice. The aim is that this research and the implications derived from it will be a step towards informed LD by teachers and the design of relevant LA tools to support the alignment between LA and LD.

\section{Declaration of Conflicting Interest}

The author(s) declared no potential conflicts of interest with respect to the research, authorship, and/or publication of this article.

\section{Funding}

The first author received financial support by a PhD fellowship from the Faculty of Educational Sciences, University of Oslo, Norway.

\section{Acknowledgments}

We wish to thank the members of the LiDA Research Group at the Department of Education, the University of Oslo for the constructive feedback on the primary data and for useful comments on a previous version of the article. We thank the anonymous reviewers and editors of this special issue for their valuable comments on our manuscript.

\section{References}

Agostinho, S. (2011). The use of a visual learning design representation to support the design process of teaching in higher education. Australasian Journal of Educational Technology, 27(6). https://https://dx.doi.org/10.14742/ajet.923

Alhadad, S. S., \& Thompson, K. (2017). Understanding the mediating role of teacher inquiry when connecting learning analytics with design for learning. Interaction Design and Architecture(s) Journal, 33, 54-74. Retrieved from https://eprints.qut.edu.au/202493/1/62149001.pdf

Andersen, R., \& Mørch, A. I. (2016). Mutual development in mass collaboration: Identifying interaction patterns in customer-initiated software product development. Computers in Human Behavior, 65, 77-91.

https://dx.doi.org/10.1016/j.chb.2016.08.005

Bakharia, A., Corrin, L., de Barba, P., Kennedy, G., Gašević, D., Mulder, R., Lockyer, L. (2016). A conceptual framework linking learning design with learning analytics. Proceedings of the $6^{\text {th }}$ International Conference on Learning Analytics and Knowledge (LAK '16), 25-29 April 2016, Edinburgh, UK (pp. 329-338). New York, NY: ACM. https://dx.doi.org/10.1145/2883851.2883944

Bennett, S., Agostinho, S., \& Lockyer, L. (2015). Technology tools to support learning design: Implications derived from an investigation of university teachers' design practices. Computers \& Education, 81, 211-220. https://dx.doi.org/10.1016/j.compedu.2014.10.016

Benesty, J., Chen, J., Huang, Y., \& Cohen, I. (2009). Pearson correlation coefficient. In I. Cohen, Y. Huang, J. Chen, \& J. Benesty (Eds.), Noise reduction in speech processing (pp. 1-4). Berlin, Germany: Springer. https://dx.doi.org/10.1007/978-3-642-00296-0_5

Buckingham Shum, S., Ferguson, R., \& Martinez-Maldonado, R. (2019). Human-centred learning analytics. Journal of Learning Analytics, 6(2), 1-9. https://dx.doi.org/10.18608/jla.2019.62.1

Bonk, C. J., \& Graham, C. R. (2012). The handbook of blended learning: Global perspectives, local designs. Hoboken, NJ: John Wiley \& Sons. Retrieved from https://books.google.no/books?hl=en\&lr=\&id=2u2TxK06PwUC\&oi=fnd\&pg=PT14\&dq=

Conole, G. (2012). Designing for learning in an open world (Vol. 4). Leicester, UK: Springer Science \& Business Media. Retrieved from https://dl.uswr.ac.ir/bitstream/Hannan/130952/1/9781441985163.pdf https://dx.doi.org/10.1007/978-14419-8517-0

Dobozy, E., \& Cameron, L. (2018). Special issue on learning design research: Mapping the terrain. Australasian Journal of Educational Technology, 34(2). https://dx.doi.org/10.14742/ajet.4390 
Eradze, M., Rodriguez Triana, M. J., \& Laanpere, M. (2017). Semantically annotated lesson observation data in learning analytics datasets: A reference model. Interaction Design and Architecture(s) Journal, 33, 75-91. Retrieved from http://www.mifav.uniroma2.it/inevent/events/idea2010/doc/33 4.pdf

Fritz, J. (2016). LMS course design as learning analytics variable. In J. Greer, M. Molinaro, X. Ochoa, \& T. McKay (Eds.), Proceedings of the $1^{\text {st }}$ Learning Analytics for Curriculum and Program Quality Improvement Workshop (PCLA 2016), 25 April 2016, Edinburgh, UK (pp. 15-19). Retrieved from https://www.semanticscholar.org/paper/LMS-CourseDesign-As-Learning-Analytics-Variable-Fritz/be7e8fe65384513355467e56cc84b36829669482

Gašević, D., Dawson, S., Rogers, T., \& Gasevic, D. (2016). Learning analytics should not promote one size fits all: The effects of instructional conditions in predicting academic success. The Internet and Higher Education, 28, 68-84. https://dx.doi.org/10.1016/j.iheduc.2015.10.002

Griffiths, D. (2017). The use of models in learning design and learning analytics. Interaction Design and Architecture(s) Journal, 33, 113-133. Retrieved from http://ubir.bolton.ac.uk/1330/1/Griffiths\%20D\%20IxD\%26A\%20article.pdf

Gunn, C., McDonald, J., Donald, C., Nichols, M., Milne, J., \& Blumenstein, M. (2017). Building an evidence base for teaching and learning design using learning analytics. Wellington, Australia: Ako Aotearoa - The National Centre for Tertiary Teaching Excellence. Retrieved from https://ako.ac.nz/assets/Knowledge-centre/NPF-15-008

Haya, P. A., Daems, O., Malzahn, N., Castellanos, J., \& Hoppe, H. U. (2015). Analysing content and patterns of interaction for improving the learning design of networked learning environments. British Journal of Educational Technology, 46(2), 300-316. https://dx.doi.org/10.1111/bjet.12264

Hernández-Leo, D., Martinez-Maldonado, R., Pardo, A., Muñoz-Cristóbal, J. A., \& Rodríguez-Triana, M. J. (2019). Analytics for learning design: A layered framework and tools. British Journal of Educational Technology, 50(1), 139152. https://dx.doi.org/10.1111/bjet.12645

Harel, D., \& Koren, Y. (2001). A fast multi-scale method for drawing large graphs. In J. Marks (Ed.) Graph drawing. GD 2000. Notes in computer science (Vol. 1984). Berlin, Germany: Springer. https://dx.doi.org/10.1007/3-540-44541$\underline{2} 18$

Ifenthaler, D., Gibson, D., \& Dobozy, E. (2018). Informing learning design through analytics: Applying network graph analysis. Australasian Journal of Educational Technology, 34(2), 117-132. https://dx.doi.org/10.14742/ajet.3767

Kaliisa, R., Mørch, A. I., \& Kluge, A. (2019). Exploring social learning analytics to support teaching and learning decisions in online learning environments. In M. Scheffel, J. Broisin, V. Pammer-Schindler, A. Ioannou, \& J. Schneider (Eds.), Transforming learning with meaningful technologies. Proceedings of the $14^{\text {th }}$ European Conference on Technology Enhanced Learning (EC-TEL 2019), 16-19 September 2019, Delft, The Netherlands. Lecture Notes in Computer Science (Vol. 11722) (pp. 187-198). Cham, Switzerland: Springer. https://dx.doi.org/10.1007/978-3-030-29736-7 14

Kaliisa, R., Kluge, A., \& Mørch, A. I. (in press a). Overcoming the challenges to learning analytics adoption at the practitioner level: A critical analysis of 18 learning analytics frameworks. Scandinavian Journal of Educational Research.

Kaliisa, R., Kluge, A., \& Mørch, A. I.. (in press b). "My point of departure for analytics is extreme skepticism": Implications derived from an investigation of university teachers' learning analytics perspectives and design practices. Technology, Knowledge \& Learning.

Knight, S., Shum, S. B., \& Littleton, K. (2014). Epistemology, assessment, pedagogy: Where learning meets analytics in the middle space. Journal of Learning Analytics, 1(2), 23-47. https://dx.doi.org/10.18608/jla.2014.12.3

Law, N., Li, L., Herrera, L. F., Chan, A., \& Pong, T.-C. (2017). A pattern language based learning design studio for an analytics informed inter-professional design community. Interaction Design and Architecture(s) Journal, 33, 92-112. Retrieved from http://www.mifav.uniroma2.it/inevent/events/idea2010/doc/33 5.pdf

Lockyer, L., Heathcote, E., \& Dawson, S. (2013). Informing pedagogical action: Aligning learning analytics with learning design. American Behavioral Scientist, 57(10), 1439-1459. https://dx.doi.org/10.1177/0002764213479367

Macfadyen, L. P., \& Dawson, S. (2010). Mining LMS data to develop an "early warning system" for educators: A proof of concept. Computers \& Education, 54(2), 588-599. https://dx.doi.org/10.1016/j.compedu.2009.09.008

Macfadyen, L. P., \& Dawson, S. (2012). Numbers are not enough: Why e-learning analytics failed to inform an institutional strategic plan. Journal of Educational Technology \& Society, 15(3), 149-163. Retrieved from https://www.jstor.org/stable/10.2307/jeductechsoci.15.3.149

Mangaroska, K., \& Giannakos, M. N. (2018). Learning analytics for learning design: A systematic literature review of analytics-driven design to enhance learning. IEEE Transactions on Learning Technologies, 12(4), 516-534.

https://dx.doi.org/10.1109/TLT.2018.2868673 
Martinez-Maldonado, R., Kay, J., Yacef, K., \& Schwendimann, B. (2012). An interactive teacher's dashboard for monitoring groups in a multi-tabletop learning environment. In S. A. Cerri, W. J. Clancey, G. Papadourakis, \& K. Panourgia (Eds.), Proceedings of the $11^{\text {th }}$ International Conference on Intelligent Tutoring Systems (ITS 2012), 14-18 June 2012, Chania, Greece,. Lecture notes in computer science (Vol. 7315) (pp. 482-492). Berlin, Germany: Springer. https://dx.doi.org/10.1007/978-3-642-30950-2 62

McKenney, S., \& Mor, Y. (2015). Supporting teachers in data-informed educational design. British Journal of Educational Technology, 46(2), 265-279. https://dx.doi.org/10.1111/bjet.12262

Michos, K., Hernández-Leo, D., \& Albó, L. (2018). Teacher-led inquiry in technology-supported school communities. British Journal of Educational Technology, 49(6), 1077-1095. https://dx.doi.org/10.1111/bjet.12696

Mor, Y., Ferguson, R., \& Wasson, B. (2015). Learning design, teacher inquiry into student learning and learning analytics: A call for action. British Journal of Educational Technology, 46(2), 221-229. https://dx.doi.org/10.1111/bjet.12273

Melero, J., Hernández-Leo, D., Sun, J., Santos, P., \& Blat, J. (2015). How was the activity? A visualization support for a case of location-based learning design. British Journal of Educational Technology, 46(2), 317-329. https://dx.doi.org/10.1111/bjet.12238

Nguyen, Q., Huptych, M., \& Rienties, B. (2018). Linking students' timing of engagement to learning design and academic performance. Proceedings of the $8^{\text {th }}$ International Conference on Learning Analytics and Knowledge (LAK '18), 5-9 March 2018, Sydney, NSW, Australia (pp. 141-150). New York, NY: ACM. https://dx.doi.org/10.1145/3170358.3170398

Nguyen, Q., Rienties, B., Toetenel, L., Ferguson, R., \& Whitelock, D. (2017). Examining the designs of computer-based assessment and its impact on student engagement, satisfaction, and pass rates. Computers in Human Behavior, 76, 703-714. https://dx.doi.org/10.1016/j.chb.2017.03.028

Paranyushkin, D. (2019). InfraNodus: Generating insight using text network analysis. Proceedings of the $28^{\text {th }}$ International Conference on World Wide Web (WWW '19), 13-17 May 2019, San Francisco, CA, USA (pp. 3584-3589). New York, NY: ACM. https://dx.doi.org/10.1145/3308558.3314123

Persico, D., \& Pozzi, F. (2015). Informing learning design with learning analytics to improve teacher inquiry. British Journal of Educational Technology, 46(2), 230-248. https://dx.doi.org/10.1111/bjet.12207

Rienties, B., Cross, S., \& Zdrahal, Z. (2017). Implementing a learning analytics intervention and evaluation framework: What works? In D. Kei Daniel (Ed.) Big data and learning analytics in higher education (pp. 147-166). Cham, Switzerland: Springer. https://dx.doi.org/10.1007/978-3-319-06520-5 10

Rienties, B., \& Toetenel, L. (2016). The impact of learning design on student behaviour, satisfaction and performance: A cross-institutional comparison across 151 modules. Computers in Human Behavior, 60, 333-341. https://dx.doi.org/10.1016/j.chb.2016.02.074

Rodríguez-Triana, M. J., Martínez-Monés, A., Asensio-Pérez, J. I., \& Dimitriadis, Y. (2015). Scripting and monitoring meet each other: Aligning learning analytics and learning design to support teachers in orchestrating CSCL situations. British Journal of Educational Technology, 46(2), 330-343. https://dx.doi.org/10.1111/bjet.12198

Samuelsen, J., Chen, W., \& Wasson, B. (2019). Integrating multiple data sources for learning analytics: Review of literature. Research and Practice in Technology Enhanced Learning, 14(11), 1-20. https://dx.doi.org/10.1186/s41039-019-0105$\underline{4}$

Shibani, A., Knight, S., \& Shum, S. B. (2019). Contextualizable learning analytics design: A generic model and writing analytics evaluations. Proceedings of the $9^{\text {th }}$ International Conference on Learning Analytics and Knowledge (LAK '19), 4-8 March 2019, Tempe, AZ, USA (pp. 210-219). New York, NY: ACM. https://dx.doi.org/10.1145/3303772.3303785

Smith, M. A., Shneiderman, B., Milic-Frayling, N., Mendes Rodrigues, E., Barash, V., Dunne, C., \& Gleave, E. (2009). Analyzing (social media) networks with NodeXL. Proceedings of the $4^{\text {th }}$ International Conference on Communities and Technologies (C\&T '09), 25-27 June 2009, University Park, PA, USA (pp. 255-264). New York, NY: ACM. https://dx.doi.org/10.1145/1556460.1556497

Wise, A. F., \& Jung, Y. (2019). Teaching with analytics: Towards a situated model of instructional decision-making. Journal of Learning Analytics, 6(2), 53-69. https://dx.doi.org/10.18608/jla.2019.62.4

Wise, A. F., \& Shaffer, D. W. (2015). Why theory matters more than ever in the age of big data. Journal of Learning Analytics, 2(2), 5-13. https://dx.doi.org/10.18608/jla.2015.22.2 